\title{
Earth systems engineering and management
}

\author{
Stephen H. Schneider
}

Imagine that we could let the world's economy continue to grow, bring the disadvantaged classes up from poverty and at the same time not threaten the atmosphere or global ecosystems with unprecedented build-up of greenhouse gases and the projected climatic risks of such growth. Earth systems engineering and management may just be such a panacea, some have suggested. But could we anticipate the costs or ever truly predict the consequences?

exr ew people would ask us to accept that a growing world economy based on greatly expanded per capita energy consumption would be free of environmental side effects. But many have claimed that the anticipated several-fold increase in greenhouse gases and associated sea-level rises, intensified hurricanes, or drought and flood stresses can be largely overcome by human ingenuity. Their optimistic vision depends greatly on what had been called 'geoengineering' and has more recently been relabelled Earth systems engineering. This describes the deliberate manipulation of the Earth system to manage the climatic consequences of human population and economic expansion ${ }^{1}$

To others, the notion of geoengineering — injecting dust in the stratosphere, for example, to reflect some sunlight back to space and counteract greenhouse warming - is an irresponsible palliative. It evades the need for a real cure, such as curbing the consumption of the rich and the population growth of the poor, and charging polluters for their use of the atmosphere as a free sewer.

In response, defenders of geoengineering retort that two-thirds of the world's people use a small fraction of the energy per capita of the rich. Cheap primary energy (mainly coal) is needed, they say, to build the economies of less developed countries and improve their well being. The negative environmental side effects of this will have to either be tolerated or be sidestepped by geoengineering in order to have it both ways - a materialistic growth-oriented world and relatively undisturbed climate.

At times this debate takes on an ideological tenor. Claims that the imperative of development cannot be impeded by the prospect of global warming are greeted with the assertion that creating inadvertent damage to nature is bad enough, but deliberately attempting to manipulate the climate just to let our old habits prevail is a violation of stewardship and an ethical transgression against the natural world. These sets of opposing world views - anthropocentric expansion versus stewardship - are not new. They flared in the 1970s with Club of Rome debates over the 'limits to growth' and matured with the publication of the Brundtland Commissions' middle path, aiming to pursue 'sustainable development'. Today, they continue in arguments over whether nations must meet their emissions reductions agreed in the Kyoto Protocol by domestic cuts - even if not cost effective - or be permitted to shop around to buy their obligations elsewhere in the world at lower costs.

Let us return to the central question of what best characterizes Earth systems engineering. Is it a panacea for sustainable development built with vision and ingenuity or a palliative to avoid fundamental limits and maintain the privileged status quo for special interests? There is no easy answer to this question, but I do believe that both sides have merit in parts of their arguments. Here I will try to sketch out some opportunities and

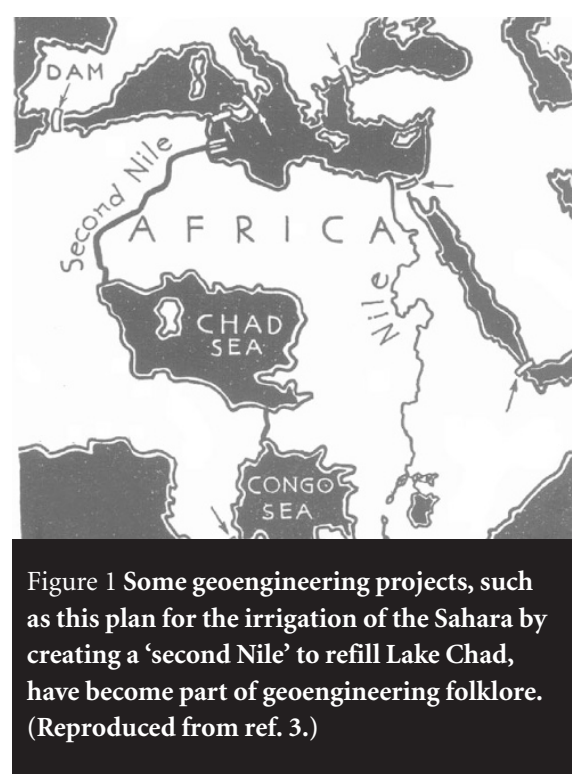

pitfalls that might help to clarify the role of geoengineering and carbon management strategies in the climate policy debate.

\section{Historical perspective}

In Homer's Odyssey, Ulysses is the frequent beneficiary (or victim) of deliberate weather modification schemes perpetuated by various gods and goddesses. In Shakespeare's The Tempest, Prospero, a mortal (albeit one with magical powers), conjures up a tempest to strand on his mystical island a passing ship's crew. In literature and myth, only gods and magicians could control the elements. But in the twentieth century, serious proposals for the deliberate modification of weather and/or climate came from engineers, futurists or those concerned with counteracting the inadvertent anthropogenic modification of the Earth's climate.

About 1960, Rusin and Flit ${ }^{3}$ from the former Soviet Union published a long essay entitled Man versus Climate in which they suggested 'improving' our planet by, for instance, diverting rivers from the Arctic to the Russian wheat fields, or from the Mediterranean to irrigate areas in Asian USSR. One of their ambitious projects was to create a 'Siberian sea' with water taken from the Caspian Sea and Aral Sea areas. Of course, flowery rhetoric with images of blooming arid zones stands in stark contrast to the ecological disaster that surrounds the Aral Sea today, where environmental degradation is associated with much less radical geoengineering projects ${ }^{4}$.

Other such proposals have become part of geoengineering folklore and include damming the Gulf Stream, the Bering Straits or the Nile, or creating a Mediterranean drain back into central Africa where a 'second Nile' would refill Lake Chad, turning it into the 'Chad Sea' after the Straits of Gibraltar were dammed (Fig. 1). But the potential side effects if these projects misfire are rarely discussedwhich is not unlikely, given the complexity of the highly nonlinear climate system. 
In the early 1970s, Russian climatologist Mikhail Budyko ${ }^{5}$ suggested that it was "incumbent on us to develop a plan for climate modification that will maintain existing climatic conditions". What he endorsed was a stratospheric particle layer to reflect away enough sunlight to counteract greenhouse warming. But, wisely, he added the caveat that deliberate climate modification would be premature before the consequences could be calculated with confidence, a task for which the current simplified theories were inadequate.

William Kellogg and I looked at many such schemes in the 1970s and concluded then ${ }^{6}$ that tampering blindly with the weather system would be the height of irresponsibility. Moreover, it would lead to disputes as any natural weather disaster occurring during deliberate climate modification experiments might well be blamed on the climate modifiers. We offered a modest proposal for 'no-fault climate-disaster insurance': if a large segment of the world thought that the benefits of a proposed climate modification scheme would outweigh the risks, they should be willing to compensate those who subsequently lost their favoured climate.

Ironically, perhaps, the term 'geoengineering' first seems to have been applied to a scheme that is nolonger called by that name. It was informally coined by Cesare Marchetti ${ }^{7}$ who outlined a proposal for tackling the problem of $\mathrm{CO}_{2}$ in the atmosphere by a kind of 'fuel cycle' for fossil fuels. Under this proposal, $\mathrm{CO}_{2}$ would be collected at certain 'transformation points' such as the smokestacks of principal fossil fuel-burning industrial centres. It would be disposed of by injection into sinking thermohaline currents (say, the Mediterranean undercurrent entering the Atlantic at Gibraltar) that would carry and spread it into the deep ocean. Today, this kind of a plan is referred to as industrial carbon sequestration, which is part of 'carbon management' - controlling the amount of greenhouse gases in the atmosphere. Geoengineering as a term has evolved to mean deliberate modifications to biogeochemical or energy flows in the climate system. This kind of tampering with natural processes, not surprisingly, inflames passionate debate.

Since Marchetti's paper, perhaps the most ambitious attempt to justify and classify a range of geoengineering options was associated with a US National Academy of Sciences (NAS) National Research Council panel on the policy implications of global warming ${ }^{8}$.

As a member of that panel, I can report that the very idea of including a chapter on geoengineering led to serious internal and external debates. Many participants (including myself) were worried that even the thought that we could offset some aspects of inadvertent climate modification by deliberate modification schemes could be used as an excuse to continue polluting. Critics instead favoured market incentives to reduce
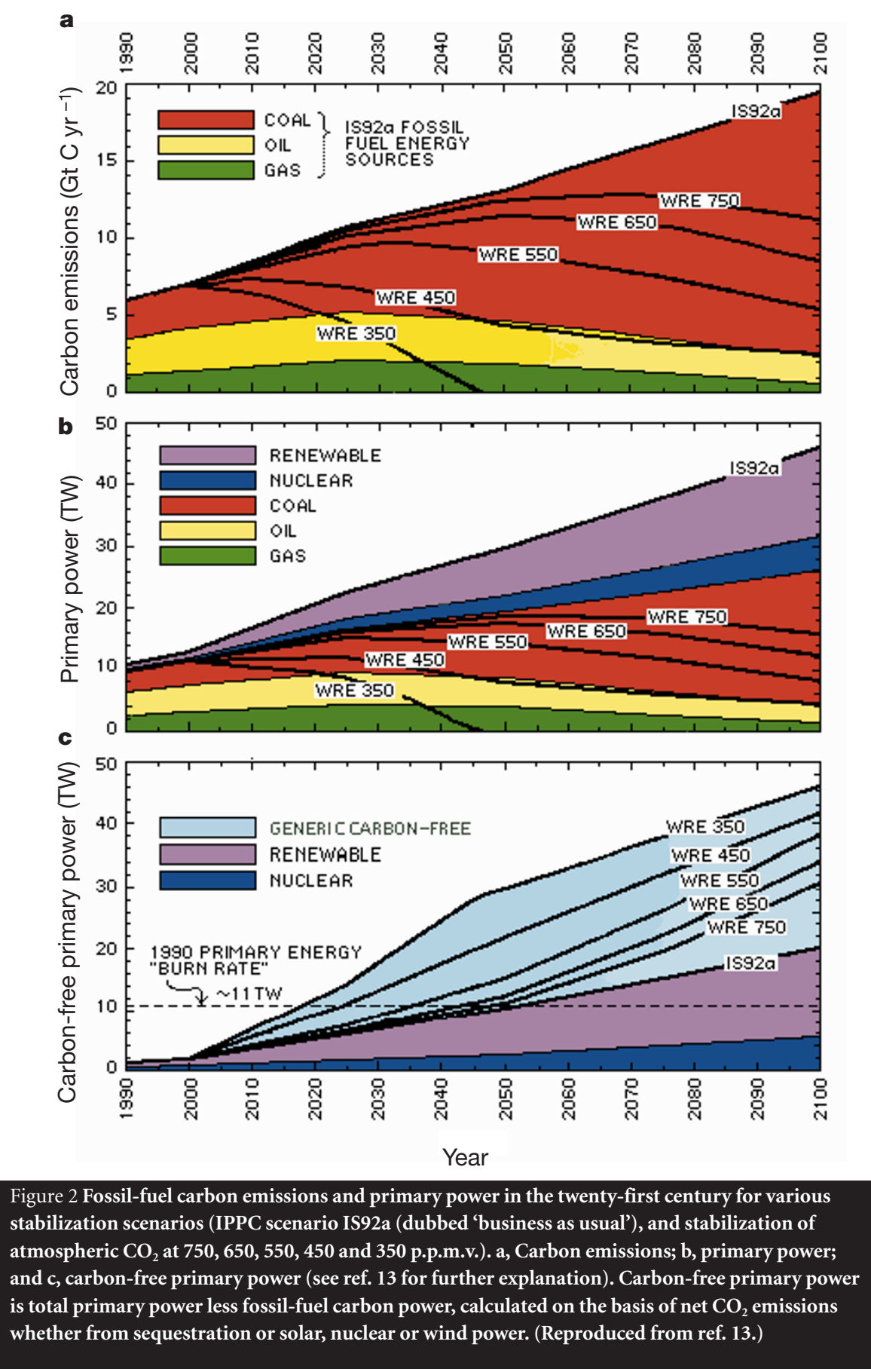

emissions or regulations for cleaner alternative technologies. But Robert Frosch countered as follows: what if a pattern of change currently thought unlikely, but of high consequence, actually started to unfold in the decades ahead? It would take decades to develop the technical and political tools to reverse the risks. We would simply have to practise geoengineering as the 'least evil'.

Although sceptical about the viability of specific engineering proposals and the questionable symbolism of suggesting that we could sidestep real reductions in emissions, I nonetheless voted reluctantly with the majority of the NAS panelists who agreed to allow a carefully worded chapter on the geo- engineering options to remain in the report.

Extending Budyko's focus on the injection of aerosol particles (particles suspended in a gas) in the stratosphere, the geoengineering chapter of the report suggested that 16 -inch naval rifles fired vertically could propel a 1-ton shell consisting of dust particles up to an altitude of 20 kilometres. Given an aerosol lifetime in the stratosphere of two years, 10 megatons $\left(10^{10}\right.$ kilograms $)$ could be placed in the stratosphere 20 times during a 40 -year period until 2030. Over this time the NAS authors estimated geoengineering costs to be about US\$5 per ton carbon (as $\mathrm{CO}_{2}$ ) mitigated. This cost is somewhat comparable to carbon taxes proposed by Nordhaus ${ }^{9}$ 


\section{insight feature}

for modest control of $\mathrm{CO}_{2}$ emissions. But for a major mitigation of $\mathrm{CO}_{2}$ emissions (for example, a 20\% cut), Nordhaus's study suggests that the carbon taxes required could be hundreds of dollars per ton carbon. (Conventional calculations of the costs of $\mathrm{CO}_{2}$ mitigation through carbon taxes use economic models that are likely to overestimate the costs of mitigation as these models still ignore the effects of climate policies in inducing technological improvements; for a critique, see ref. 10.)

But is it even possible to inject dust in the stratosphere, for example, in a manner that would perfectly offset a given injection of greenhouse gases in the atmosphere? Even though the $30 \%$ increase in $\mathrm{CO}_{2}, 150 \%$ increase in methane, and the addition of unnatural chemicals such as chlorofluorocarbons have spread fairly uniformly over every square metre of the Earth since the industrial revolution, the patterns of heat trapped as a consequence are not uniform. The primary reason is the non-uniform distribution of other optically active constituents of the atmosphere, especially clouds.

Furthermore, humans add aerosols as well - not primarily the stratospheric kind, but mostly tropospheric sulphate aerosols resulting from the burning of coal and oil. These short-lived, lower-atmospheric aerosols are patchy in distribution and probably reject sunlight back to space at the rate of up to 1 watt per square metre averaged over the Northern Hemisphere ${ }^{11}$, enough to offset perhaps one-quarter to one-half of the extra infrared heat associated with the enhanced greenhouse effect globally. And biomass burned also produces patchy distributions of aerosols, some of which actually warm the climate since they contain light-absorbing soot, as do some industrial aerosols as well.

Because of the patchy nature of the greenhouse effect itself, even if we could engineer our stratospheric aerosol injections to balance on a hemispheric (or global) basis the amount of hemispherically (or globally) averaged heat trapped by humancontributed greenhouse gases, we would still be left with some regions heated to excess and others left cooler. I am not saying that such anomalies arising from aerosol geoengineering would necessarily be worse than, say, an unabated $5^{\circ} \mathrm{C}$ warming. But this is why the strong caveats in the NAS report are reiterated by all responsible people who have addressed the question.

As a postscript to this question, a climatic model study at the Lawrence Livermore National Laboratory ${ }^{12}$ has actually attempted to simulate whether the zonal patterns of stratospheric aerosol cooling could offset the more patchy patterns of greenhouse gas heating. They concluded optimistically that within the sampling precision of the model - which is still quite noisy - the aerosol scheme might not generate major regional climatic anomalies relative to those of unabated climatic change. Although not definitive, such studies are needed to give confidence in the effectiveness of any geoengineering scheme. And without high confidence in the outcome, any implementation would be controversial or indeed lead to overt conflicts - the subject we turn to next.

\section{Caretakers for a century?}

No institutions currently have the authority to enforce responsible use of the global commons. There are some partially successful examples of nation states willing to cede some national sovereignty to international authorities for the global good (for instance, the Montreal Protocol and its extensions to control ozone-depleting substances, the nuclear non-proliferation treaty, or the atmospheric nuclear test-ban treaty). The Kyoto Protocol, even if ratified (currently a dubious prospect), would address only a small fraction of the needed emissions cuts if $\mathrm{CO}_{2}$ concentrations are to be stabilized below a doubling from pre-industrial levels (much of the primary energy needed in 2050 will have to be mobilized with carbon emissions well below current standards, or huge efforts made to remove the excess ${ }^{13}$ ) (Fig. 2).

It would require a big increase in 'globalmindedness' on the part of most nations to set up institutions to attempt to control climate and to compensate the losers should the interventions backfire - or even be perceived to have gone awry. Moreover, such an institution would need the resources and authority to make and monitor changes over a century or two - the time it will take the climate system to soak up the bulk of the greenhouse gasses we have injected. Thus, this is the time over which we would continuously need to inject measured amounts of dust in the stratosphere, iron in the oceans ${ }^{14,15}$ or sulphate aerosols into clouds in order to counteract the heat-trapping effects of longlived constituents such as $\mathrm{CO}_{2}$.

So the most difficult obstacle in the path of geoengineering may be questionable governance rather than technical uncertainties ${ }^{16}$.

\section{Varieties of carbon management}

Two broad classes of carbon management can be distinguished. The first includes attempts to manipulate natural biogeochemical processes of carbon removal - so-called 'carbon sinks ${ }^{17}$. The second involves preventing carbon emissions into the atmosphere and instead disposing of it in (one hopes) stable reservoirs. David Keith (see Box 1) suggests that the dividing line between geoengineering and mitigation is when a technology acts by counterbalancing an anthropogenic forcing rather than by reducing it.

Carbon management by manipulating biogeochemical cycles overlaps with geoengineering. Ideas include iron fertilization

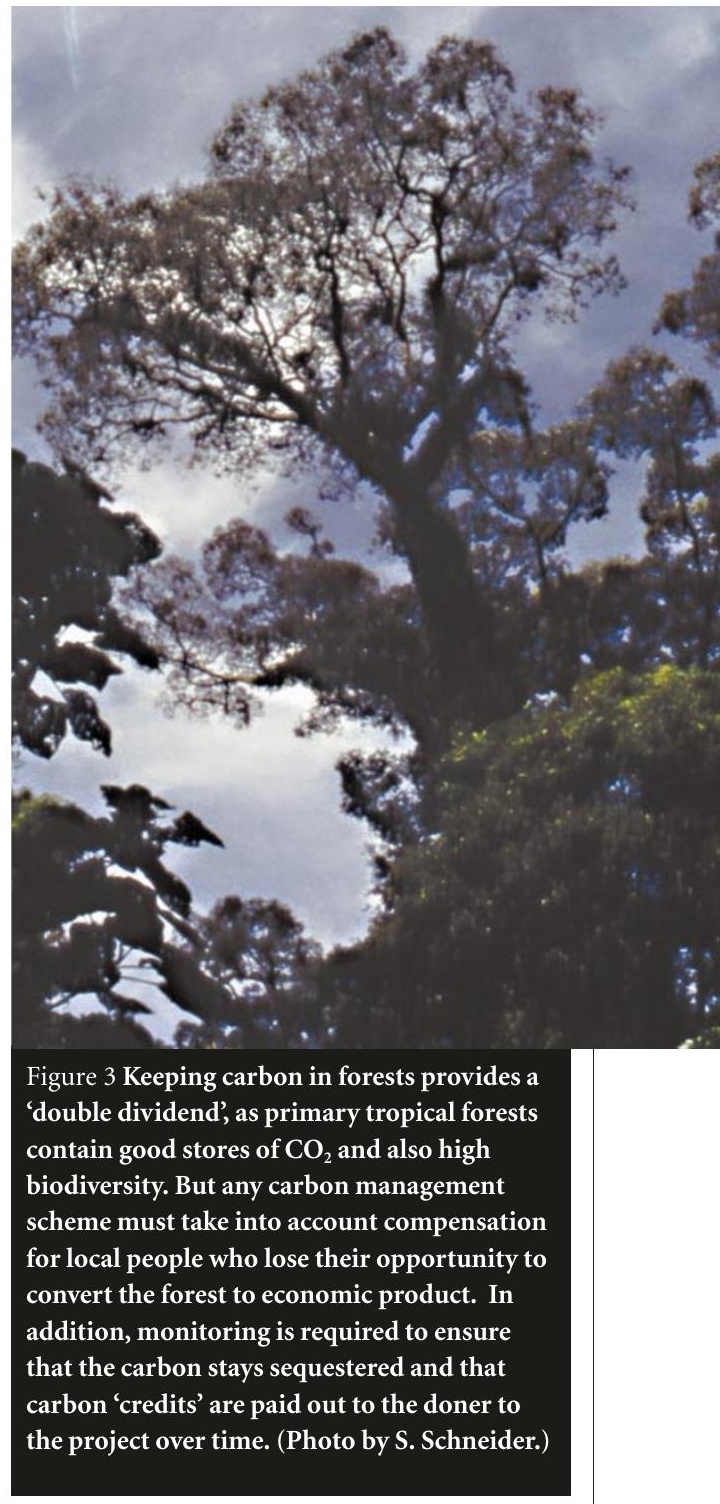

of the oceans to enhance uptake of carbon by the resulting blooms of phytoplankton, planting vast forests of fast-growing trees to sequester carbon ${ }^{18}$ or altering agricultural practices to increase carbon storage in soils ${ }^{19}$.

The prevention of carbon emissions that otherwise would have been injected directly into the atmosphere is not geoengineering. Briefly, it includes preservation of primary forests that otherwise might have been cut down (which also helps to preserve biodiversity) (Fig. 3); industrial processing to increase the hydrogen content and remove carbon from fuels such as coal or methane, and subsequent injection of the carbon into storage reservoirs; and using less carbonintensive energy supply systems and improving energy efficiency. The last two of these, of course, is what has come to be called 'mitigation', and is usually favoured by environmentalists. (The climate policy debate typically argues the costs of mitigation versus adaptation, although geoengineering has been mentioned as a third category from the outset.) 


\section{Geoengineering}

\section{David W. Keith}

Geoengineering is planetary-scale environmental engineering, particularly engineering aimed at counteracting the undesired side effects of other human activities ${ }^{1}$. The term has usually been applied to proposals for limiting the climatic impact of industrial $\mathrm{CO}_{2}$ emissions by countervailing measures such as the construction of space-based solar shields. Scale and intent are both central to the common meaning of geoengineering as the following examples demonstrate. First, intent without scale: ornamental gardening is the intentional manipulation of the environment to suit human desires, yet it is not geoengineering because neither the intended nor the realized effect is large-scale. Second, scale without intent: anthropogenic $\mathrm{CO}_{2}$ emissions will change global climate, yet they are not geoengineering because they are a side effect of the use of fossil fuels to provide energy services.

The distinction between geoengineering and more conventional responses to the $\mathrm{CO}_{2}$-climate problem is fuzzy. Geoengineering has become a label for technologically overreaching proposals that are omitted from serious consideration in climate assessments. For example, few would object to applying the label to the first pair of examples below, but neither proposal rates serious consideration among climate policy-makers. Conversely, the second pair do receive serious consideration but few would call them geoengineering.

\section{Geoengineering proposals Enhancing oceanic sinks}

Concept. Fertilizing the 'biological pump' may enhance the flux of carbon into the oceans that maintains the disequilibrium in $\mathrm{CO}_{2}$ concentration between the atmosphere and the deep ocean. While use of nitrogen and phosphorus has been proposed, iron fertilization is the salient possibility because the ratio of iron addition to carbon fixation is very large (the Fe:C ratio is $\sim 1: 10^{4}$ whereas for $\mathrm{N}: \mathrm{C}$ it is $\sim 1: 6$ ). Status. Iron-fertilization experiments have produced marked increases in oceanic productivity ${ }^{2}$, and surveys have shown that biological productivity is iron-limited over substantial areas $^{3}$. Although enhancement of surface productivity is possible, increasing the carbon flux into the deep ocean is highly uncertain - models suggest that even if iron fertilization was used at the largest possible scale

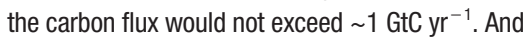
problems abound, as iron fertilization could produce anoxia in large regions of the deep ocean.

\section{Shielding some sunlight}

Concept. Warming due to anthropogenic greenhouse gases can be countered by deploying systems in the stratosphere or in space that scatter sunlight away from the planet. Stratospheric scatters are much cheaper but entail risks to stratospheric chemistry; space-based systems offer an expensive but clean alteration of the solar 'constant'. Status. Analysis has shown that it is possible to dramatically reduce the required mass and thus the

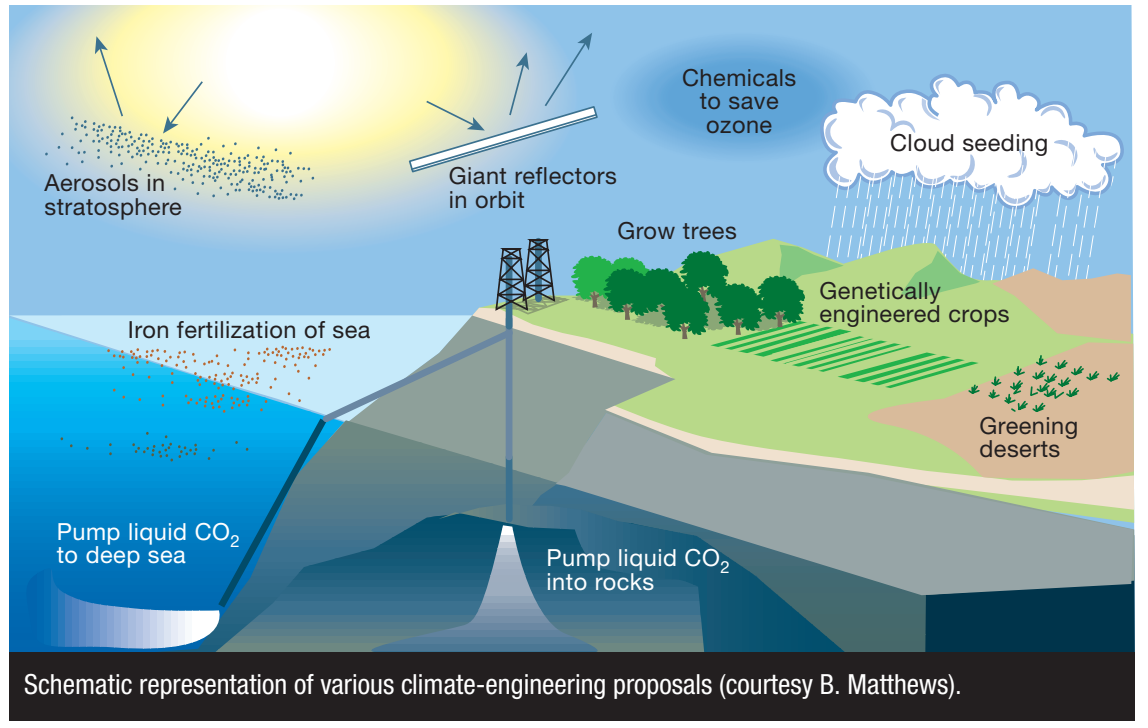

cost of both scattering systems ${ }^{4}$. It had long been suggested that changes to the solar constant would compensate only poorly for the climatic effects of increased $\mathrm{CO}_{2}$, even if mean surface temperature was accurately controlled. But a recent climate model experiment indicates that reduction of solar input can compensate for increased $\mathrm{CO}_{2}$ with remarkable fidelity ${ }^{5}$.

\section{Ambiguous Cases}

\section{Enhancing terrestrial sinks}

Concept. Given the substantial human control over the terrestrial biosphere, the large natural carbon fluxes between atmosphere and terrestrial biosphere provide a powerful lever for manipulating atmospheric $\mathrm{CO}_{2}$. A great diversity of methods have been proposed to exploit this leverage including reforestation and sequestration in agricultural soils via 'zero-till' methods or via the genetic modification of cultivars to enhance lignin content ${ }^{6}$. Is it geoengineering? Enhancement of terrestrial sinks has been seen as green and low-tech in sharp contrast with geoengineering. The idea has garnered wide support in industry and among environmental organizations. Yet, if implemented at the scale required to capture a significant fraction of emissions, terrestrial sequestration would resemble planetaryscale environmental engineering and may well entail high-tech methods such as genetic modification of crops. The divergent treatment of terrestrial and oceanic sinks illustrates the inconsistencies that pervade discussion of planetary engineering.

\section{Sequestering $\mathrm{CO}_{2}$}

Concept. We may use fossil energy without emissions of $\mathrm{CO}_{2}$ by first capturing the carbon content of fossil fuels while generating carbon-free energy products such as electricity and hydrogen and then sequestering the resulting $\mathrm{CO}_{2}$ in geological formations or in the ocean ${ }^{7}$

Is it geoengineering? The term geoengineering was coined in the 1970s to describe the injection of power-plant $\mathrm{CO}_{2}$ into the deep ocean. Despite this etymology it is unclear whether capture and sequestration is rightly classified as geoengineering. It is certainly an end-of-pipe technical fix, but (arguably) injection into geological reservoirs resembles conventional pollution-mitigation technologies more closely than it resembles geoengineering, because it limits emission of $\mathrm{CO}_{2}$ to the biosphere rather than compensating for emissions after they occur. Put simply: if geological sequestration is end-of-pipe then biological sequestration is beyond-the-pipe.

\section{Commentary}

The post-war growth of the earth sciences has been fuelled, in part, by a drive to quantify environmental insults in order to support arguments for their reduction. Yet paradoxically the knowledge gained is increasingly granting us leverage that may be used to deliberately engineer environmental processes at planetary scale. The manipulation of solar flux using stratospheric scatterers is perhaps the best example of this leverage: we could reduce solar input by several per cent - probably sufficient to initiate an ice age - at an annual cost of less than $0.01 \%$ of global economic output ${ }^{1,4}$. As remedies for the $\mathrm{CO}_{2}$-climate problem, all proposed geoengineering schemes have serious flaws. Nevertheless, I judge it likely that this century will see serious debate about — and perhaps implementation of — deliberate planetary-scale engineering.

David W. Keith is in the Department of Engineering and Public Policy, Carnegie Mellon University, Pittsburgh, Pennsylvania, USA. (e-mail: Keith@cmu.edu)

1. Keith, D. W. Annu. Rev. Energy Environ. 25, 245-284 (2000). 2. Boyd, P. W. et al. Nature 407, 695-702 (2000).

3. Behrenfeld, M. J. \& Kolber, Z. S. Science 283, 840-843 (1999). 4. Teller, E., Wood, L. \& Hyde, R. Report no. UCRL-JC-128157 (Lawrence Livermore National Laboratory, Livermore, CA, 1997). 5. Govindasamy, B. \& Caldeira, K. Geophys. Res. Let. 27, 2141-2144 (2000).

6. Rosenberg, N. J., Izaurralde, R. C. \& Malone, E. L. Carbon

Sequestration in Soils: Science, Monitoring, and Beyond (Battelle, Columbus, OH, 1998)

7. Parson, E. A. \& Keith, D. W. Science 282, 1053-1054 (1998). 
One idea is to build on the chemical industry's existing experience of industrial-scale carbon removal and sequestration. Nitrogen fertilizer, for example, is manufactured when carbon fuels such as natural gas or gasified coal are converted to secondary energy carriers such as hydrogen - although this is not done for the purpose of using the clean-burning hydrogen as a fuel, but rather for chemical processing. And as carbon-intensive fuels such as coal are progressively converted to more hydrogenbased fuels such as methane, carbon dioxide is a by-product that needs to be sequestered in a stable reservoir. The oil industry, too, has long experience with $\mathrm{CO}_{2}$ sequestration through advanced oil recovery schemes. With one exception, these are not aimed at reducing atmospheric emissions of $\mathrm{CO}_{2}$. Nonetheless, this experience can be built upon to develop carbon management for climate purposes.

The feasibility of $\mathrm{CO}_{2}$ sequestration below ground has already been explored at small scales. The Sleipner West offshore platform in the North Sea operated by the Norwegian company Statoil is an interesting experiment in which about 1 million tons of $\mathrm{CO}_{2}$ annually is stripped out of the natural gas mixture brought out of the earth. The $\mathrm{CO}_{2}$ is re-injected into an aquifer about 1,000 metres below the ocean surface. As the $\mathrm{CO}_{2}$ spreads along this geological formation, eventually - perhaps over hundreds of years — it may leak out, but this slow re-injection back into the climate system will avoid the acute build up of $\mathrm{CO}_{2}$ that would have occurred under normal circumstances. Most interesting, perhaps, is why this first-of-akind plant was built: Norway had instituted a tax on carbon emissions of around US $\$ 100$ dollar per ton carbon, and it seems that the costs of $\mathrm{CO}_{2}$ removal and sequestration might be cheaper than paying the tax.

This, of course, is the crux of the climate policy debate: how can we create incentives to put a price on carbon or other heattrapping gases? Debate rages about whether to provide incentives directly by a carbon tax, or indirectly via targets and timetables (as in the Kyoto Protocol), or via subsidies to companies willing to develop carbon management schemes. But without such incentives, the extent to which technological options will be explored is questionable.

Carbon management thinkers have also suggested that industrial efforts should not be restricted to centralized sources such as power plants or oil platforms, but must consider distributed applications such as transportation systems. Perhaps we will see the development of a few centralized plants to produce hydrogen fuel for zero-emission vehicles. To be cost-effective, such plants would need to be in areas with abundant resources of fossil fuels and adequate storage reservoirs for the waste carbon ${ }^{1}$. However, some have questioned whether sequestered carbon will remain buried, and thus whether carbon credits should be given unless it is proved that the storage is lasting. To eliminate endless debate I propose an inexpensive fix: to add into the injected $\mathrm{CO}_{2}$ an inert chemical tracer unique to each sequestration site. Thus, the non-detection of this tracer over time would serve to certify that carbon credit is deserved for such sequestration projects.

\section{'Strong' or 'weak' engineering}

In 1992 at the Rio Environment Summit the United Nations Framework Convention on Climate Change committed the nations of the world to avoid 'dangerous anthropogenic interference with the climate system'. At that time the thinking was primarily about inadvertent modification. But now it seems that world leaders may have to extend their value judgement about what is 'dangerous' to deliberate interference with the climate system.

Naturally, there is a philosophical debate about whether there is anything ethically wrong with such tinkering. On the one hand, we have progressed from hunting and gathering, it is argued, by increasingly large-scale manipulations of the natural environment. In fact, some environmental writers have despaired that an altered climate is already 'The End of Nature ${ }^{\text {'20 }}$. It has been argued that Earth systems engineering and management is the approach "to rationally engineer and manage [the Earth] to provide the requisite functionality", and that this is not a logical transgression of naturalness since the Earth is already "an artefact" of our manipulations ${ }^{21}$. Of course, anything other than a preservation of current structure and function demands a definition of 'improvement', and this judgement will be very different across diverse cultures.

Moreover, there are still areas in the polar regions and deep tropical rainforest where there is "essentially no visible human imprint; where the majority of species have evolved in situ... and where biochemical perturbations are small"22. Such landscapes are not 'artificial' simply because a slight global climatic change has already occurred. We should avoid disrupting them further, rather than using 'light perturbation' as an excuse to turn over the future of all nature to the 'functionality' of the planetary managers.

Given our growing inadvertent impact on the planet, adaptation alone may prove inadequate. But I would prefer to reduce slowly our economic dependence on carbon fuels, rather than to try to counter the potential side effects with centuries of injecting sulphuric acid into the atmosphere or iron into the oceans. Laying stress instead on carbon management, with little manipulation of biogeochemical or energy fluxes in nature, is a much less risky prospect despite remaining uncertainties about the longevity of deep earth or ocean carbon storage, possible ecological consequences of localized injections of vast quantities of $\mathrm{CO}_{2}$ in the oceans or the potential damper on global economic development. If preliminary studies prove reasonable, then the cost penalties for closing the industrial cycles by reinserting waste $\mathrm{CO}_{2}$ back in the earth might be only a few tens of per cent of current energy system costs - something akin to US\$50-100 per ton carbon. The actual costs of various forms of carbon management will be crucial in determining how much climate change we and the unmanaged environment will have to adapt to in the decades ahead. But until national governments cooperate and provide incentives to both producers and users of climate-altering products, the potential for any carbon management enterprise will be restricted and the likelihood of 'dangerous' climatic changes increased.

To me, any form of 'stronger' Earth systems engineering and management is a revision of Rusin and Flit's fantasy of 40 years ago to transform the Earth system to achieve 'improvements in climate.' Those wishing to usurp the province of ancient gods and conjurers should recall the ancient Greeks' warnings about human hubris embodied in the story of Prometheus.

Stephen H. Schneider is in the Department of Biological Sciences and Institute for International Studies, Stanford University, Stanford, California 94305-5020, USA

1. Socolow, R. (ed.) Fuels Decarbonization and Carbon Sequestratio PU/CEES Rep. No. 302, September 1997

<http://www.princeton.edu/ ceesdoe/> (Centre for Engineering and Environmental Studies, Princeton University, 1997).

2. World Commission on Environment and Development. Our Common Future (Oxford Univ. Press, Oxford, 1987).

Rusin, N. \& Flit, L. Man versus Climate (Peace Publishers, Moscow, 1960). [Translated from Russian by D. Rottenberg.]

4. Glazovsky, N. F. The Aral Crisis: The Origin and Possible Way Out (Naulca, Moscow, 1990).

Budyko, M. I. Climate Changes 244 (American Geophysical Union, Washington DC, 1977). [Translated from Russian.]

6. Kellogg, W. W. \& Schneider, S. H. Science 186, 1163-1172 (1974). Marchetti, C. Clim. Change 1, 59-68 (1977).

8. Panel on Policy Implications of Greenhouse Warming, Committee on Science, Engineering, and Public Policy, National Academy of Sciences. Policy Implications of Greenhouse Warming: Mitigation, Adaptation, and the Science Base 433-464 (National Academy Press, Washington DC, 1992).

9. Nordhaus, W. D. Science 258, 1315-1319 (1992).

10. Grubb, M., Duong, M. H. \& Chapuis, T. in Integrative Assessment of Mitigation, Impacts and Adaptation to Climate Change CP-94-9 (eds Nakícenovic, N., Nordhaus, W. D. Richels, R. \& Toth, F. L.) 513-534 (International Institute of Applied Systems Analysis, Laxenberg, Austria, 1994).

11. Intergovernmental Panel on Climate Change. IPCC Working Group I, Second Scientific Assessment, 1995 (Cambridge Univ. Press, Cambridge, 1995).

12. Govindasamy, B. \& Caldeira, K. Geophys. Res. Let. 27, 2141-2144 (2000).

13. Hoffert, M. I. et al. Nature 395, 881-884 (1998)

14. Watson, A. J. et al. Nature 371, 143-145 (1994).

15. Monastersky, R. Science News 148, 220-222 (1995).

16. Schneider, S. H. Clim. Change 33, 291-302 (1996).

17. Intergovernmental Panel on Climate Change. Land Use, LandUse Change, and Forestry (eds Watson, R. T. et al.) (Cambridge Univ. Press, Cambridge, 2000).

18. Johansson, T. B., Kelly, H., Reddy, A. K. N. \& Williams, R. H. (eds) Renewable Energy: Sources for Fuels and Electricity (Island, Washington DC, 1993)

19. Rosenberg, N. J., Izaurralde, R. C. \& Malone, E. L. (eds) Carbon Sequestration in Soils: Science, Monitoring and Beyond (Proc. St Michaels Workshop, Dec. 1998) (Batelle, Columbus, OH, 1999). 20. McKibben, W. The End of Nature (Random House, New York, 1989). 21. Allenby, B. J. Indust. Ecol. 2, 73-93 (1999).

22. Keith, D. W. IEEE Technol. Soc. Mag. 19, 25-28 (2000). 